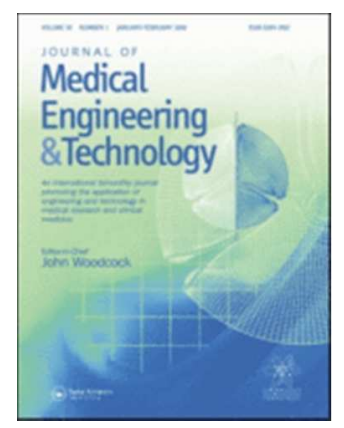

\title{
Strain distribution on a finger link: A static simulation study
}

\begin{tabular}{|r|l|}
\hline Journal: & Journal of Medical Engineering \& Technology \\
\hline Manuscript ID & TMET-2017-0116.R1 \\
\hline Manuscript Type: & Authors' Response to Decision Letter \\
\hline Complete List of Authors: & $\begin{array}{l}\text { Liu, Jiawen; University of Southampton Faculty of Physical Sciences and } \\
\text { Engineering, School of Electronic and Computer Science } \\
\text { Chappell, Paul; University of Southampton, School of Electronics and } \\
\text { Computer Science } \\
\text { White, Neil; University of Southampton Faculty of Physical Sciences and } \\
\text { Engineering, School of Electronic and Computer Science }\end{array}$ \\
\hline Keywords: & prosthetic hand, strain sensor, simulation, Southampton hand \\
\hline &
\end{tabular}

\section{SCHOLARONE}

Manuscripts 


\title{
Strain distribution on a finger link: A static simulation study
}

\author{
Jiawen Liu, Paul Chappell, Neil White \\ Department of Electronics and Computer Science, University of Southampton, \\ Southampton, United Kingdom; SO17 1BJ
}

Jiawen Liu is a postgraduate student of the Department of Electronic and Computer Science, University of Southampton. E-mail: j136g11@ecs.soton.ac.uk

Dr. Paul Chappell and Prof. Neil White are academic staff of Department of Electronic and Computer Science, University of Southampton. E-mail: phc@ecs.soton.ac.uk, 


\section{Strain distribution on a finger link: A static simulation study}

Functional prosthetics hands which have the ability to help amputees perform tasks in daily life have been developed over many years. These hands need A control system which is fed information from sensors mounted on a prosthetic hand and human-machine interface, are a key aspect of future system. A variety of sensors therefore been developed for the prosthetic hand to measure fingertip force, joint angle(position), object slip, texture and temperature.

However, most of the strain/stress sensors are attached to the fingertip. In this paper, the potential positions for strain sensors on the side of the finger link of the prosthetic hand are investigated that, in the future, will allow for force control in a lateral or key grip. With modified links of a Southampton Hand, some promising areas-positions for strain sensors were-have been determined. On some of the links, the strain sensor can be used as an indicator to show the angle of the finger during a curling operation.

Keywords: prosthetic hand; simulation; Southampton hand; strain sensor; piezoresistive sensor

\section{Introduction}

Prosthetics development has a long history, which may are thought to have started from the age of ancient Egyptians[1] where wood and leather were used. In contrast a mordern $A$ functional artificial hand, which can enhance amputees and adapt to their environment or tasks, uses composite materials, alloys and polymers.is always drawing media attention. A raised public awareness of disability means that artificial hands are always drawing attention from the media. An example of a multifunctional hand is The Southampton Hand that has been under developed development for 
several decades $[2,3,4,5,6,7,8,9,10,11]$. One of the first designs was back in 1970s by Professor J. M. Nightingale[12, 13]. The project then continued with further

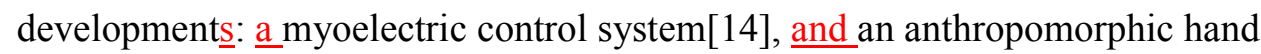
system with electrical-electronic controller, driver and multiple axes was developed $[15,16]$. Sensors for different functions have been investigated for the detection of contact force, slip temperature and texture[17, 18]. Information from these sensors is-was sent to an electronic myoelectric controller[19]. Most of the sensors are-were designed to be integrated on the surface of a fingertip or thumb tip. The sensors described in this paper are mounted on the lateral side of a finger and have the possibility of using them in the control of force in a lateral or key grip posture. Here the thumb opposes the lateral side of the first finger. A thumb could also oppose sensors mounted on the side of the other fingers.

The development of sensors has become one of the most important issues in the improvement of prosthetic hand systems[20]. The first commercial hand with sensors was the SensorHand ${ }^{\mathrm{TM}}$ Speed[21]. It has-had only one movement where the fingers and thumb can close together. Its sensors, however, can provide signals that tell the controller when the object begins to slip, so more power will be added to maintain the grip[22]. In recent years, different types of tactile sensors have-had been developed: Resistive-resistive sensors, piezoresistive sensors[23, 24, 25, 26, 27, 28, 29 , 30, 31, 32, 33, 34, 35], capacitive sensors[36, 37, 38, 39, 40, 41, 42] and piezoelectric sensors[43, 44, 45, 46, 47, 48]. These sensors are-were made from different materials such as polymers and graphene. The size varies-varied from typical one tenth of a 
millimetre hundreds of micrometres-to tens of millimetres. Force, slip, strain, pressure, temperature and some other properties can be detected by some of these sensors.

Table 1 shows a brief classification of the sensors in previous research.

[Table 1 here]

The sensors are-were designed to be mounted on the surface of the fingertip or links which are-were parallel to the surface of the palm when the hand is was expanded fully. The sensory inputs of the sensors are-were mainly perpendicular with these surfaces. In this paper, the side surfaces of the finger links were investigated to find any promising positions for a strain sensor to sense in the abduction/adduction direction.

The finger link system shown in figure 1 is a part of the Southampton Hand. It has one degree of freedom which flexes and extends the finger. This mechanism of two four-bar linkages was first designed by Guo, Lee and Gruver[49], and it was also used in Light's study[9]. The finger is driven by a mini-motor, which is connected via a gearbox to link OB. The gearbox, a worm-wheel system transmits power and drive $\underline{\text { link OB by rotating around the main axle. Then the other parts of the link system are }}$ driven by link OB. A full description of this mechanism can be found in [50]

In the original design (2005), different kinds of sensors ean bewere mounted on a fingertip[17]. A strain sensor is-was used to sense an external load which is-was perpendicular to the top surface of the fingertip. The force applied to the fingertip while the prosthetic hand was griping an object or touching a surface can then be detected. However, in some scenarios, such as holding a cup of coffee, the direction 
of the external load can also be in this paper, the response of an externalload which is perpendicular to the operation plane of the finger link system (shown in Figure 1

(bottom)) is described. In this paper, the response of the finger link system to this kind of load is described. A strain sensor is located on the side link to detect the response. -

To investigate the position for a strainthis sensor-to detect this respense, the link system can be modified to maximize the strain distribution.

[Figure 1 here]

\section{Simulation}

\subsection{Finger link modification}

An investigation of the strain distribution required the modification of three links. In To erder to maintain the original curling transition of a finger, the geometry was not altered. A cuboid structure is cut out of the link to reduce the-its thickness of the link. There will be more strain around these cut areas, which increases the sensitivity for a given force of applied to a strain sensor. In each simulation, only one of the links is modified with the other links kept to the original thickness to maintain the strength of the link system. An area of one link surface slides on an adjacent link surface (link ACD and link $\mathrm{OB})$. They push together if the load is applied and the contact between the two links would-influences the strain distribution on these linksthem. Sø these links are under investigation, the cut cuboid structure on it is-also included-

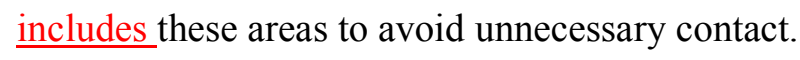

[Figure 2 here] 
(1) Link DF:

A cuboid structure $(15 \mathrm{~mm} \times 6 \mathrm{~mm} \times 1.2 \mathrm{~mm})$ is reduced from the original design to form a $15 \mathrm{~mm} \times 6 \mathrm{~mm} \times 0.8 \mathrm{~mm}$ beam. (Figure 2 left)

(2) Link BCE:

As link BCE is in the middle between side links (Link DF and Link ACD), the structure is reduced in cross section from both sides. A $15 \mathrm{~mm} \times 6 \mathrm{~mm} \times 0.8 \mathrm{~mm}$ beam is formed. (Figure 2 middle)

(3) Link ACD:

In the original design, the clear range between the planar surfaces of link ACD and link $\mathrm{OB}$ is only $0.1 \mathrm{~mm}$ on other side of link OB. As mentioned before, the deformation of link ACD under the specific load will make direct contact with link OB. Thus ${ }_{2}$ in this situation, the contact point will become a supporting point of the beam. So-Hence the structure is reduced at the inner side of link ACD (Figure 2 right). The relative position of link $\mathrm{ACD}$ and link $\mathrm{OB}$ is changing during the curling operation of the finger. To avoid direct contact, a longer structure $(31 \mathrm{~mm} \times 6 \mathrm{~mm} \times 0.8 \mathrm{~mm})$ is cut. For both links ACD, the structure is reduced from the inner side of the link. (Figure 2 right)

Several simulations were carried out to investigate the safety factor. To successfully reduce the thickness and find the point at which the link yields. The minimum safety factor on the modified link is above 2.2. 


\subsection{Simulation set up}

The Stress Analysis package of Autodesk Inventor ${ }^{\circledR}$ was used to undertake Finite Element Analysis of the structure. The knuckle block is set as a fixed constraint and is bonded to fixed unmovable surfaces. A $50 \mathrm{~N}$ external load is applied to the side surface of the fingertip. Under normal operation, the load on the finger will be around $5-10 \mathrm{~N}$, but the load may reach $50 \mathrm{~N}$ or even more in some circumstances, such as when an amputee stumbles and the prosthetic hand is used to stop a fall. Hence, a $50 \mathrm{~N}$ external load is applied on the side surface on the fingertip where the direction and the position of the load is shown in figure 1 (bottom). The material of the links is aluminium alloy and the axles and screws are manufactured from stainless steel. Table 2 shows the mechanical properties of the aluminium alloy and stainless steel.

[Table 2 here]

Local mesh control is applied on the surface of the modified link and the position where the sensor may be attached. A finer mesh $(0.5 \mathrm{~mm}$ element size $)$ is applied on these surfaces to obtain results with a higher resolution. The size of the mesh is applied to the whole finger except for the modified link which is larger to reduce the simulation time.

To study the response of the link system during the whole range of a 'elosing curling of the handa finger' operation from full extension to full flexion, eight positions were-are simulated. The angle between the top surface of link OB and the top surface of Knuckle Block is used to indicate these positions as shown in Figure 3.

[Figure 3 here] 


\section{Results \\ 3.2 1 Simulation results of the modified link DF}

Strain distribution (0 degree) on the outer surface of modified link DF is shown in figure 5a $\underline{4 a}$. The black line on the link is called the probe line, which indicates the position of the strain probes. The $\mathrm{x}$ axis is along the probe line and the origin is at the left end of the probe line. The starting point of the probe line is $4 \mathrm{~mm}$ away from the centre of the left hole on the link. The length of this line is longer than the length of the cut-out structure described in section $2.2 \underline{1}$ and figure $3 \underline{2}(\mathrm{left})$. It shows the main strain area on the link. Figure $5 b \underline{b} \underline{b}$ shows the strain value on the probe line during the elose-curling operation and figure $5 \mathrm{c} \underline{4 \mathrm{c}}$ shows the distribution change.

[Figure 4 here]

In addition, it is found that the strain distribution on link BCE also shows a result that should be assessed. The starting point of the probe line is $5 \mathrm{~mm}$ away from the centre of the left hole on the link. Strain distribution ( 0 degree) on the outer surface of link BCE is shown in figure 5a. Figure $5 \mathrm{~b}$ shows the strain value on the probe line during the curling operation and the strain distribution change is shown in figure 5c.

[Figure 5 here]

\section{3-2 Simulation results of the modified link $A C D$}

The starting point of the probe line is $6.5 \mathrm{~mm}$ away from the centre of the left hole on

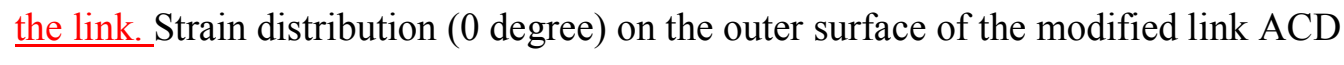


is shown in figure $6 \mathrm{a}$. Figure $6 \mathrm{~b}$ shows the strain value on the probe line during the closing operation. Strain distribution change is shown in figure $6 c$.

[Figure 6 here]

\section{4-3 Simulation results of the modified link BCE}

The starting point of the probe line is $5 \mathrm{~mm}$ away from the centre of the left hole on the link. Strain distribution (0 degree) on the outer surface of modified link BCE is shown in figure $7 \mathrm{a}$. Figure $7 \mathrm{~b}$ shows the strain value on the probe line during the close operation. Strain distribution change is shown in figure $7 \mathrm{c}$.

[Figure 7 here]

Additionally, the strain data is collected at a certainthree positions, $\mathrm{x}=1 \mathrm{~mm}$, $\mathrm{x}=3 \mathrm{~mm}$ and $\mathrm{x}=5 \mathrm{~mm}$. These data are shown in figure 8 .

[Figure 8 here]

\subsection{Simulation results of modified Link DF (sensor on Link BCE)}

Strain distribution ( 0 degree) on the outer surface of link BCE is shown in figure $9 a$. Figure $9 b$ shows the strain value on the probe line during the close operation Strain distribution change is shown in figure $9 \mathrm{c}$.

[Figure 9 here] 


\section{Discussion}

\subsection{Shape change of a loaded link}

For a simple cantilever, where one end is attached to a table surface and a load is applied on the other free end, it will be bent into a curve. However, if a load is applied on the side of a fingertip, the deformation of the link part will not be a simple curve. The three link parts will support each other and form a complicated displacement of the fingertip compared to only one link connected to the fingertip. A simplified model was built to explain this situation. The three links are placed parallel and two connectors are used to replace the link parts that are connected to the three parts in the original design. Figure 9a shows the simplified model.After a load is applied to the fingertip, the link is deformed to a special shape that is not like a simple cantilever where, for example, one end is attached to a table surface and a load is applied on theother free end. To explain this result, a simplified module was built. This wasabstracted from the original finger link design. To eliminate the twist that may happen when loaded, the three linked parts were placed in the same plane. The other parts are connected to the knuckle block. Figure $4 a$ shows the simplified module.

[Figure 4-9 here]

The left side is then fixed, and load is applied on the right side. The result is shown in figure $4 \mathrm{~b} \underline{9 \mathrm{~b}}$ :

Two opposite curves occurred on the link part. Hence both a tensile area and compressed area were seen on the link. The right-side pivot was moved along the direction of curve $x$ that is almost parallel with the direction of the load. Hence, on the 
side link part, the forces which are provided by the bolts and the contact area between link parts can be simplified into four forces. They are shown in the figure $4 \mathrm{e} \underline{\mathrm{c}}$. The four forces can lead to the two curves of the link mentioned before.

In the original link system, a similar situation occurred on each link- where Both both a tensile area and a compressed area were seen on itcan be seen. It is here-at $\underline{\text { this position that it is a-possible to place the strain sensor to detect lateral force. }}$

\subsection{Discussion of the results}

It can be seen that in-In each situation, the tensile strain (red colour) and compressed strain (blue colour) ean beare found on the link parts. Tensile strain locates near the Knuckle Block side while compressed strain locates near the fingertip side. A neutral line (green colour) lies between them. The magnitude and shape of the strained area changes during a closing $\underline{\text { curling operation. In the following, situation }}$ we case-only one link is modified while the others are unmodified.

\section{- Case 1: Modified link DF, Probe line on link DF:}

Compared with the other modified links, the strain magnitude remains stable over all angles. The average standard deviation is 56.4 micro strain. But the-The shape of the tensile strain area (shown in red) changes during a elosing curling operation. At $\underline{\text { From }}$ $\underline{0 \text { degrees to }} 70$ degrees, the strain above the probe line is becoming higher than that under the probe line. During a close operation from 0 -50 degree, the strain on the left side varies (at the same position, the strain drops a little during the operation) whilethe strain on the right side remains almost the same. There is increased compressive 
strain when the link system is at 60-70 degree. The values at these two angles are $17.8 \%$ and $18.7 \%$ higher than the average of other 6 angles respectively. almost remain the same. The average strain difference is $1.55 \times 10^{-5}$, the maximum strain difference is $5.7 \times 10^{-5}$ and the minimum strain difference is $1 \times 10^{-6}$.

- Case 2: Modified link DF, Probe line on link BCE:

The tensile strain magnitude decreases and the position of peak value of compressed strain moves from right to left during a closing operation. The zero-strain point also $\underline{\text { moves from right to left during the close operation. The value difference between } 0 \text { to }}$ 20 degrees is much smaller compared with the other angles. The value difference between 40 and 50 degrees is also much smaller. The average strain difference is $1.60 \times 10^{-5}$, the maximum strain difference is $3 \times 10^{-4}$ and the minimum strain difference is 0

- Case $z \underline{3}$ : Modified link ACD, Probe line on link ACD:

The strain decreases along the probe line between 0 and 20 degrees. The strain at $\underline{x}=5 \mathrm{~mm}$ drops $54 \%$ while the finger curling from 40 degrees to 70 degrees. The shape of tensile area and compressed area also changed significantly. The strain at 70 degrees is very small compared with the 0 -degree situation. It can be seen that the strain along the probe line changes a lot while the finger link is curling. So that it is not a suitable place at which to place a sensor.

- Case 34: Modified link BCE, Probe line on link BCE: 
The zero-strain point moves from right to left during the close operation. The strain over the range, from $x=1 \mathrm{~mm}$ to $x=8 \mathrm{~mm}$, shows a linear response while the finger is curling from 20 to 70 degrees. The data shown in figure 8 are the strain at position $x=1 \mathrm{~mm}, \mathrm{x}=3 \mathrm{~mm}$ and $\mathrm{x}=5 \mathrm{~mm}$. This linear relationship between strain and angle shows a possible indicator for the angle of the link. The method can be described as below: There are three variables: strain, angle of the link and external load. Using the data from two sensors, the angle can be determined, knowing the strain and external load. A sensor placed at the fingertip or on link DF could determine the external load. Another sensor placed on link BCE could estimate the strain. Hence, the angle can then be calculated. The strain gradually decreases from $30-70$ degrees. Around thepoint $x=11 \mathrm{~mm}$, the strain is almost the same during the operation. The zero-strain point moves from right to left during the close operation.

On the other hand, the strain over the range, from $x=1 \mathrm{~mm}$ to $x=8 \mathrm{~mm}$, shows a linear respense while the finger is curling from 20 to 70 degrees. The data shown in figure 8 are the strain at position $x=1 \mathrm{~mm}, x=3 \mathrm{~mm}$ and $x=5 \mathrm{~mm}$. This linear relationship between strain and angle shows a possible indicator for the angle of the link. The method can be deseribed as below: There are three variables: strain, angle of the link and external load. Using the data from two sensors, the angle can bedetermined, Knowing the strain and external load. $\Lambda$ sensor placed at the fingertip or on link DF could determine the external load. Another sensor placed on link BCE could estimate the strain. Hence, the angle can then be calculated. - Case 4: Modified link DF, Probe line on link BCE: 
The tensile strain magnitude decreases and the position of peak value of compressed strain moves from right to left during a closing operation. The zero-strain point alsomoves from right to left during the close operation. The value of the strain from 0 to 20 -degrees are almost the same and the value of the strain at 40 and 50 degrees arealmost the same. The average strain difference is $1.60 \times 10^{=5}$, the maximum strain difference is $3 \times 10^{-4}$ and the minimum strain difference is $\theta$

The area that is suitable for a strain sensor requires two main characteristics, the differences of the strain distribution during the curling and whether the area only contains tensile or compressive strain. The detailed position of the sensor can only be determined if the size and pattern of the sensor is known. The sensor should cover the peak strain point and should not exceed zero strain point. According to the results shown before (figure $5 \underline{4}-9 \underline{8}$ ), the area that can be used to put a sensor on are:

In case 1: The tensile strain area is from the point $x=0$ to the point $x=10 \mathrm{~mm}$. The peak is at $\mathrm{x}=1.4 \mathrm{~mm}$. The compressed strain area is from the point $\mathrm{x}=11 \mathrm{~mm}$ to the point $\mathrm{x}=16 \mathrm{~mm}$ and the peak is at $\mathrm{x}=15.6 \mathrm{~mm}$. The opposite type of strain area can be found at the same position on the other side of the link. The strain remains stable during the operation.

In case 2: The tensile strain area is from the point $x=0$ to the point $x=7 \mathrm{~mm}$. The compressed strain area is from the point $x=14 \mathrm{~mm}$ to the point $\mathrm{x}=24 \mathrm{~mm}$. The strain also decreases during the close operation but not gradually. There is no suitableplace to put a sensor. 


\begin{abstract}
from the point $x=0$ to the point $x=7 \mathrm{~mm}$. The compressed strain area is from the point
\end{abstract} $\mathrm{x}=8 \mathrm{~mm}$ to the point $\mathrm{x}=15 \mathrm{~mm}$. The strain gradually decreases during the operation sothat the strain may be able to indicate the angle of the link system.

In case 4: The tensile strain area is from the point $x=0$ to the point $x=7 \mathrm{~mm}$.

The compressed strain area is from the point $x=8 \mathrm{~mm}$ to the point $\mathrm{x}=15 \mathrm{~mm}$. The strain gradually decreases during the operation so that the strain may be able to indicate the angle of the link system.

The tensile strain area is from the point $x=0$ to the point $x=7 \mathrm{~mm}$. The compressed strain area is from the point $x=14 \mathrm{~mm}$ to the point $x=24 \mathrm{~mm}$. The strain also decreases during the close operation but not gradually.

A force sensor placed on the lateral side of a finger, for example on the outside of a little finger could also be used as a control input[13]. Tapping the hand on a surface, e.g. a table, could generate a binary code to select a specified posture, such as a flat hand. Similarly, a lateral sensor on the side of the thumb could be used as a $\underline{\text { control input. }}$

$\underline{\text { Recently, artificial intelligence techniques are used to observe the complicated }}$ relationship between multiple inputs and multiple outputs. By placing a series of sensors on an artificial hand, their signals could be gathered as inputs and the different positions of the digits of the hand could be treated as outputs. Thus, a connection between the signals and the posture of the hand can be established with the help of $\underline{\text { artificial intelligence techniques. }}$ 


\section{Conclusion}

An increase in the sensitivity of lateral sensor is achieved by modifying the links. The links are modified to increase the sensitivity of the strain on it. Good-Potential areas for to position a strain sensor were found on the lateral side of link DFseveral of the links. Both the compressive and tensile area are found on link DF where the output signal is independent of curling angle. The peak strain points were found at $\mathrm{x}=$ $1.4 \mathrm{~mm}$ for tensile area and $\mathrm{x}=15.6 \mathrm{~mm}$ for compressed areas for a link with a length of $36 \mathrm{~mm}$. Due to the gradual change of strain distribution during the elosea curling operation of the link system, the lateral strain sensors, as well as measuring force, could also be used in combination to estimate joint angle. the strain senser is able toindicate the angle of the link system with the assistance of another sensor that can provide the magnitude of the load.

Acknowledgements

The authors wish to acknowledge that the design of the finger is attributed to the late, Dr Andy Cranny.

\section{References}

1. Thurston AJ. Pare and prosthetics: The early history of artificial limbs. Anz J Surg. 2007 Dec;77(12):1114-1119. PubMed PMID: WOS:000250519100014; English.

2. Barkhordar M. Control of a Multifunctional Hand Prosthesis [ $\mathrm{PhD}$ thesis]: University of Southampton; 1989. 
3. Todd R. Adaptive Control of a Hand Prosthesis [Phd thesis]: University of Southampton; 1971.

4. Storey N. Control of an Arm Prosthesis [PhD thesis]: University of Southampton; 1978.

5. Moore D. Development of a Multifunctional Adaptive Hand Prosthesis $[\mathrm{PhD}$ thesis]: University of Southampton; 1981.

6. Swain I. Adaptive Control of an Arm Prosthesis [PhD thesis]: University of Southampton; 1982.

7. Brown DJ. The Design of an Externally-Powered Prosthetic Arm [PhD thesis]: University of Southampton; 1983.

8. Kyberd PJ. Algorithmic Control of a Multifunction Hand Prosthesis [PhD thesis]: University of Southampton; 1990.

9. Light CM. An Intelligent Hand Prosthesis and Evaluation of Pathological and Prosthetic Hand Function [PhD thesis]: University of Southampton; 2000.

10. Ahmad SA. Moving Approximate Entropy and Its Application to the Electromyographic Control of an Artificial Hand [PhD thesis]: University of Southampton; 2009.

11. Nightingale JM. Microprocessor control of an artificial arm. Journal of Microcomputer Applications. 1985 1985/04/01/;8(2):167-173. doi: https://doi.org/10.1016/0745-7138(85)90015-6.

12. Nightingale JM. An intelligent hand prosthesis; the implications for robotics [Conference Paper]. Colloquium on 'Prosthetics and Robotics'. 1983 1983:1/1-1/3. PubMed PMID: INSPEC:2106106; English.

13. Codd RD, Nightingale JM, Todd RW. An adaptive multi-functional hand prosthesis [Article]. J Physiol. 1973 Jul;232(2):55P-56P. PubMed PMID: 4727089; PubMed Central PMCID: PMCPMC1350408.

14. Kyberd PJ, Chappell PH. The Southampton Hand - an Intelligent Myoelectric Prosthesis. J Rehabil Res Dev. 1994;31(4):326-334. PubMed PMID: WOS:A1994PV60500006; English. 
15. Light CM, Chappell PH. Development of a lightweight and adaptable multiple-axis hand prosthesis [Article]. Med Eng Phys (UK). 2000 Dec;22(10):679-684. doi: 10.1016/s1350-4533(01)00017-0. PubMed PMID: WOS:000168714400001; English.

16. Kyberd PJ, Light C, Chappell PH, et al. The design of anthropomorphic prosthetic hands: a study of the Southampton Hand. Robotica (UK). 2001 Nov.-Dec.;19:593-600. PubMed PMID: INSPEC:7148819; English.

17. Cranny A, Cotton DPJ, Chappell PH, et al. Thick-film force, slip and temperature sensors for a prosthetic hand [Article]. Meas Sci Technol. 2005 Apr;16(4):931-941. doi: 10.1088/0957-0233/16/4/005. PubMed PMID: WOS:000228699600007; English.

18. Chappell PH, Elliott JA. Contact force sensor for artificial hands with a digital interface for a controller [Article]. Meas Sci Technol. 2003

Aug;14(8):1275-1279. doi: 10.1088/0957-0233/14/8/312. PubMed PMID: WOS:000184917300014; English.

19. Light CM, Chappell PH, Hudgins B, et al. Intelligent multifunction myoelectric control of hand prostheses. J Med Eng Technol. 2002 Jul-Aug;26(4):139-46. doi: 10.1080/03091900210142459. PubMed PMID: 12396328.

20. Lai JCK, Schoen MP, Gracia AP, et al. Prosthetic devices: challenges and implications of robotic implants and biological interfaces. P I Mech Eng H. 2007 Feb;221(H2):173-183. PubMed PMID: WOS:000244988400008; English.

21. ottobock. SensorHand Speed 2016. Available from: https://professionals.ottobockus.com/c/Sensor-Hand-Speed-w-Flex/p/8E41 58 $\underline{-\mathrm{R} 7 \% 201 \sim 24-\mathrm{F}}$

22. Sensor Hand Speed $\mathbb{R}$ - Grasping quickly and with precision! [cited 2017 June 20th]. Available from: https://professionals.ottobockus.com/media/pdf/646D321-GB-06-1602w.pdf 
23. Kane BJ, Cutkosky MR, Kovacs GTA. A traction stress sensor array for use in high-resolution robotic tactile imaging [Article]. J Microelectromech Syst. 2000 Dec;9(4):425-434. doi: 10.1109/84.896763. PubMed PMID: WOS:000166597800003; English.

24. Saha B, Baek S, Lee J. Highly Sensitive Bendable and Foldable Paper Sensors Based on Reduced Graphene Oxide. ACS Appl Mater Interfaces. 2017 Feb;9(5):4658-4666. doi: 10.1021/acsami.6b10484. PubMed PMID: WOS:000393848900044; English.

25. Hwang ES, Seo JH, Kim YJ. A polymer-based flexible tactile sensor for both normal and shear load detections and its application for robotics [Article]. $\mathrm{J}$ Microelectromech Syst. 2007 Jun;16(3):556-563. doi: 10.1109/jmems.2007.896716. PubMed PMID: WOS:000247219200008; English.

26. da Silva JG, de Carvalho AA, da Silva DD. A strain gauge tactile sensor for finger-mounted applications [Article]. IEEE Trans Instrum Meas. 2002 Feb;51(1):18-22. doi: 10.1109/19.989890. PubMed PMID: WOS:000174412900004; English.

27. Mei T, Li WJ, Ge Y, et al. An integrated MEMS three-dimensional tactile sensor with large force range [Article; Proceedings Paper]. Sens Actuator A-Phys. 2000 Mar;80(2):155-162. doi: 10.1016/s0924-4247(99)00261-7. PubMed PMID: WOS:000085819000009; English.

28. Noda K, Hoshino K, Matsumoto K, et al. A shear stress sensor for tactile sensing with the piezoresistive cantilever standing in elastic material [Article; Proceedings Paper]. Sens Actuator A-Phys. 2006 Mar;127(2):295-301. doi: 10.1016/j.sna.2005.09.023. PubMed PMID: WOS:000236448500014; English.

29. Wisitsoraat A, Patthanasetakul V, Lomas T, et al. Low cost thin film based piezoresistive MEMS tactile sensor [Article; Proceedings Paper]. Sens Actuator A-Phys. 2007 Sep;139(1-2):17-22. doi: 10.1016/j.sna.2006.10.037. PubMed PMID: WOS:000249678000005; English. 
30. Park CS, Park J, Lee DW. A piezoresistive tactile sensor based on carbon fibers and polymer substrates [Article; Proceedings Paper]. Microelectron Eng. 2009 Apr-Jun;86(4-6):1250-1253. doi: 10.1016/j.mee.2008.12.072. PubMed PMID: WOS:000267273300209; English.

31. Orengo G, Giovannini L, Latessa G, et al. Characterization of piezoresistive sensors for goniometric glove in hand prostheses. New York: Ieee; 2009. English. (2009 1st International Conference on Wireless Communication, Vehicular Technology, Information Theory and Aerospace \& Electronic Systems Technology, Vols 1 and 2).

32. Kalantari M, Ramezanifard M, Ahmadi R, et al. A piezoresistive tactile sensor for tissue characterization during catheter-based cardiac surgery [Article]. Int $\mathrm{J}$ Med Robot Comput Assist Surg. 2011 Dec;7(4):431-440. doi: 10.1002/rcs.413. PubMed PMID: WOS:000298885300007; English.

33. Ahmed M, Chitteboyina MM, Butler DP, et al. MEMS Force Sensor in a Flexible Substrate Using Nichrome Piezoresistors [Article]. IEEE Sens J. 2013 Oct;13(10):4081-4089. doi: 10.1109/jsen.2013.2272881. PubMed PMID: WOS:000324497400012; English.

34. Koiva R, Zenker M, Schurmann C, et al. A highly sensitive 3D-shaped tactile sensor. 2013 Ieee/Asme International Conference on Advanced Intelligent Mechatronics. IEEE ASME International Conference on Advanced Intelligent Mechatronics. New York: Ieee; 2013. p. 1084-1089.

35. Stassi S, Cauda V, Canavese G, et al. Flexible Tactile Sensing Based on Piezoresistive Composites: A Review [Review]. Sensors. 2014 Mar;14(3):5296-5332. doi: 10.3390/s140305296. PubMed PMID: WOS:000336783300078; English.

36. Nafari A, Ghavanini FA, Bring M, et al. Calibration methods of force sensors in the micro-Newton range [Article]. J Micromech Microeng. 2007 Oct;17(10):2102-2107. doi: 10.1088/0960-1317/17/10/023. PubMed PMID: WOS:000249810800024; English. 
37. Schmitz A, Maggiali M, Randazzo M, et al. A prototype fingertip with high spatial resolution pressure sensing for the robot iCub [Conference Paper]. 2008 8th IEEE-RAS International Conference on Humanoid Robots (Humanoids 2008). 2008 2008:423-428. doi: 10.1109/ichr.2008.4755988. PubMed PMID: INSPEC:10475763; English.

38. Pritchard E, Mahfouz M, Evans B, et al., editors. Flexible capacitive sensors for high resolution pressure measurement. 2008 IEEE Sensors; 2008 26-29 Oct. 2008.

39. da Rocha JGV, da Rocha PFA, Lanceros-Mendez S. Capacitive Sensor for Three-Axis Force Measurements and Its Readout Electronics [Article; Proceedings Paper]. IEEE Trans Instrum Meas. 2009 Aug;58(8):2830-2836. doi: 10.1109/tim.2009.2016366. PubMed PMID: WOS:000268033000055; English.

40. Muhammad HB, Recchiuto C, Oddo CM, et al. A capacitive tactile sensor array for surface texture discrimination [Article]. Microelectron Eng. 2011 Aug;88(8):1811-1813. doi: 10.1016/j.mee.2011.01.045. PubMed PMID: WOS:000293663400041; English.

41. Tiwana MI, Shashank A, Redmond SJ, et al. Characterization of a capacitive tactile shear sensor for application in robotic and upper limb prostheses [Article]. Sens Actuator A-Phys. 2011 Feb;165(2):164-172. doi: 10.1016/j.sna.2010.09.012. PubMed PMID: WOS:000288108500004; English.

42. Wang YC, Xi KL, Liang GH, et al. A Flexible Capacitive Tactile Sensor Array for Prosthetic Hand Real-Time Contact Force Measurement [Proceedings Paper]. 2014 Ieee International Conference on Information and Automation (Icia). 2014:937-942. PubMed PMID: WOS:000363815200171; English.

43. Dargahi J. A piezoelectric tactile sensor with three sensing elements for robotic, endoscopic and prosthetic applications [Article]. Sens Actuator 
A-Phys. 2000 Mar;80(1):23-30. doi: 10.1016/s0924-4247(99)00295-2.

PubMed PMID: WOS:000085661300004; English.

44. Lang SB, Muensit S. Review of some lesser-known applications of piezoelectric and pyroelectric polymers [Review]. Appl Phys A-Mater Sci Process. 2006 Nov;85(2):125-134. doi: 10.1007/s00339-006-3688-8. PubMed PMID: WOS:000240519900005; English.

45. Cotton DPJ, Chappell PH, Cranny A, et al. A novel thick-film piezoelectric slip sensor for a prosthetic hand [Article]. IEEE Sens J. 2007 May-Jun;7(5-6):752-761. doi: 10.1109/jsen.2007.894912. PubMed PMID: WOS:000246780600019; English.

46. Takamuku S, Gomez G, Hosoda K, et al. Haptic discrimination of material properties by a robotic hand [Conference Paper]. 2007 6th IEEE International Conference on Development and Learning. 2007 2007:Z75-Z80. PubMed PMID: INSPEC:9800959; English.

47. Li CY, Wu PM, Lee $\mathrm{S}$, et al. Flexible dome and bump shape piezoelectric tactile sensors using PVDF-TrFE copolymer [Article; Proceedings Paper]. J Microelectromech Syst. 2008 Apr;17(2):334-341. doi: 10.1109/jmems.2007.911375. PubMed PMID: WOS:000258996600010; English.

48. Seminara L, Capurro M, Cirillo P, et al. Electromechanical characterization of piezoelectric PVDF polymer films for tactile sensors in robotics applications [Article]. Sens Actuator A-Phys. 2011 Sep;169(1):49-58. doi:

10.1016/j.sna.2011.05.004. PubMed PMID: WOS:000293112700007; English.

49. Guo G, Zhang J, Gruver WA. Optimal Design of a Six-Bar Linkage with One Degree of Freedom for an Anthropomorphic Three-Jointed Finger Mechanism. Proceedings of the Institution of Mechanical Engineers, Part H: Journal of Engineering in Medicine. 1993 1993/09/01;207(3):185-190. doi: 10.1243/PIME_PROC_1993_207_291_02. 
50. Chappell PH. Mechatronic Hands : Prosthetic and Robotic Design. Stevenage, UNITED KINGDOM: Institution of Engineering \& Technology; 2016. 
Table 1, a brief classification of the sensors in previous research

\begin{tabular}{|c|c|c|c|c|c|c|c|}
\hline $\begin{array}{c}\text { Reference } \\
\text { No. }\end{array}$ & Year & Functional material & $\begin{array}{c}\text { Base/matrix/protection } \\
\text { material }\end{array}$ & Size & $\begin{array}{l}\text { No. of } \\
\text { sensing } \\
\text { element }\end{array}$ & Working range & Sensitivity \\
\hline$[13]$ & 2002 & $\begin{array}{c}\text { Strain gauge } \\
\text { Excel, type TA-13- } \\
\text { 060HB-350L }\end{array}$ & Hard aluminum & $16.9 \times 14.9 \times 1.6 \mathrm{~mm}$ & 2 & $0-100 \mathrm{~N}$ & $0.12 \mathrm{~V} / \mathrm{N}$ \\
\hline [14] & 2007 & $\mathrm{Cu}-\mathrm{Ni}$ & Polyimide/PDMS & $35 \times 35 \mathrm{~mm} \times 70 \mu \mathrm{m}$ & $8 \times 8$ & $0-4 \mathrm{~N}$ & $0.064 \mathrm{~V} / \mathrm{N}$ \\
\hline [15] & 2017 & Reduced graphene oxide & paper & $\begin{array}{c}1 \times 25 \mathrm{~mm} \\
\text { (can be designed as any shape) }\end{array}$ & & $6 \%$ strain & $66.6 \pm 5$ (gauge factor) \\
\hline [16] & 2000 & Polysilicon piezoresistor & & $\begin{array}{l}\text { Bridge } 22 \times 12 \times 2.35 \mu \mathrm{m} \\
\text { Plate } 100 \times 100 \times 2.85 \mu \mathrm{m}\end{array}$ & $64 \times 64$ & $0-32 \mathrm{~N}$ & $0.04-0.05 \mathrm{Mv} / \mathrm{kPa}$ \\
\hline$[17]$ & 2000 & Integrated piezoresistor & & $4 \times 4 \mathrm{~mm} \times 70 \mu \mathrm{m}$ & $4 \times 8$ & $0-10 \mathrm{~N}$ & $\begin{array}{l}13 \mathrm{mV} / \mathrm{N} \text { Normal force } \\
2.3 \mathrm{Mv} / \mathrm{N} \text { shear force }\end{array}$ \\
\hline [18] & 2006 & Doped silicone & PDMS & $\begin{array}{l}30 \times 150 \mu \mathrm{m} \text { membrane } \\
110 \times 300 \mu \mathrm{m} \text { cantilever }\end{array}$ & & $-5-5 \mathrm{kPa}$ & $1.3 \times 10^{-3} \Omega / \mathrm{kPa}$ \\
\hline [19] & 2006 & Indium tin oxide & & $200 \times 200 \mu \mathrm{m}$ & & $0-200$ & $0.1-0.2 \mathrm{Mv} / \mu \mathrm{N}$ \\
\hline [20] & 2009 & Carbon Fiber & PDMS & $10 \times 10 \times 2 \mathrm{~mm}$ & $5 \times 5$ & $0.1-0.3 \mathrm{~N}$ & $\begin{array}{l}5.88 \% / 0.1 \mathrm{~N} \\
(\Delta R / R) / \mathrm{N}\end{array}$ \\
\hline [21] & 2009 & & & & & $-90^{\circ}-60^{\circ}$ & $\begin{array}{l}67.8 \Omega / \text { degree }\left(-90^{\circ}-0\right) \\
36.7 \Omega / \text { degree }\left(0-30^{\circ}\right) \\
10 \Omega / \text { degree }\left(30^{\circ}-60^{\circ}\right)\end{array}$ \\
\hline [22] & 2011 & & & $\begin{array}{l}6 \mathrm{~mm} \text { diameter (bigger sensor) } \\
6 \mathrm{~mm} \text { diameter (smaller sensor) }\end{array}$ & & $0-25 \mathrm{~N}$ & $\pm 125 \mathrm{~N} / \mathrm{m}$ \\
\hline [23] & 2013 & $\mathrm{Ni}-\mathrm{Cr}$ & $\begin{array}{c}\text { Polyimide } \\
\mathrm{Si}_{3} \mathrm{~N}_{4} \text { passivation } \\
\text { layer } \\
\mathrm{Al}_{2} \mathrm{O}_{3} \text { membrane } \\
\text { layer }\end{array}$ & $20 \times 20 \mathrm{~mm}$ & 48 & $0-2.8 \mathrm{mN}$ & $0.266-2.248 \mathrm{~V} / \mathrm{m}$ \\
\hline [24] & 2013 & & & 3D free-form shape & & $0-10 \mathrm{~N}$ & \\
\hline [26] & 2014 & & & $2 \times 2 \mathrm{~mm}$ & & Micro-N & \\
\hline [27] & 2008 & Silicone foam & & Whole finger tip & 2 & $<0.13 \mathrm{~N} / \mathrm{mm}^{2}$ & \\
\hline [28] & 2008 & Parylene C & polyimide & $\begin{array}{l}250 \mu \mathrm{m} \text { diameter } \\
500 \mu \mathrm{m} \text { diameter }\end{array}$ & $5 \times 5$ & & $\begin{array}{l}0.03 \mathrm{fF} / \mathrm{kPa} \\
0.17 \mathrm{fF} / \mathrm{kPa}\end{array}$ \\
\hline [29] & 2009 & rubber & & $26 \times 26 \times 1.21 \mathrm{~mm}$ & ( & $\begin{array}{c}0-200 \mu \mathrm{m} \\
\text { displacement }\end{array}$ & $0.6 \mathrm{fF} / \mu \mathrm{m}$ \\
\hline [30] & 2011 & air & $\begin{array}{l}\text { Highly doped single } \\
\text { crystal silicon, PDMS }\end{array}$ & $500 \times 400 \mu \mathrm{m}$ & & & \\
\hline [31] & 2011 & & & & & $\pm 4 \mathrm{~N}, \pm 2 \mathrm{~N}$ & $\begin{array}{c}0.214 \mathrm{fF} / \mathrm{N} \text { (in range } \\
\pm 2 \mathrm{~N} \text { ) }\end{array}$ \\
\hline [32] & 2014 & $\begin{array}{l}\text { Polyethylene terephthalate } \\
\text { film } \\
\text { Copper electrode }\end{array}$ & PDMS & $\begin{array}{c}50 \times 50 \mathrm{~mm} \text { sensor area } \\
1 \times 1 \times 0.7 \mathrm{~mm} \text { sensing element area }\end{array}$ & $8 \times 8$ & $0-3000 \mathrm{mN}$ & $\begin{array}{c}4.82 \% 0 / \mathrm{mN}(0-100 \mathrm{Mn}) \\
0.23 \% 0 / \mathrm{mN}(100- \\
3000 \mathrm{Mn})\end{array}$ \\
\hline [37] & 2008 & PVDF-TrFE & & $\begin{array}{c}0.25 \mathrm{~mm}^{2} \text { Dome shape } \\
1 \mathrm{~mm}^{2} \text { Dome shape } \\
2.25 \mathrm{~mm}^{2} \text { Dome shape } \\
500 \mu \mathrm{m} \text { Bump shape } \\
1 \mathrm{~mm} \text { diameter Bump shape } \\
1.5 \mathrm{~mm} \text { diameter Bump shape }\end{array}$ & & $0-1000 \mathrm{mN}$ & $\begin{array}{r}0.81 \mathrm{mV} / \mathrm{N} \\
3.23 \mathrm{mV} / \mathrm{N} \\
9.1 \mathrm{mV} / \mathrm{N} \\
1.1 \mathrm{mV} / \mathrm{N} \\
5.07 \mathrm{mV} / \mathrm{N} \\
10.6 \mathrm{mV} / \mathrm{N}\end{array}$ \\
\hline
\end{tabular}

URL: http://mc.manuscriptcentral.com/tmet Email: John.Woodcock@CardiffandVale.wales.nhs.uk 
1

2

3

4

5

6

7

8

9

10

11

12

13

14

15

16

17

18

19

20

21

22

23

24

25

26

27

28

29

30

31

32

33

34

35

36

37

38

39

40

41

42

43

44

45

46

47

48

49

50

51

52

53

54

55

56

57

58

59

60 . .

Table 2, Mechanical properties of aluminium alloy and stainless steel.

\begin{tabular}{|c|c|c|c|c|c|}
\hline Material & Young's Modulus & Poisson's Ratio & Shear Modulus & Yield Strength & Tensile Strength \\
\hline aluminium alloy & $68.90 \mathrm{GPa}$ & 0.33 & $25.86 \mathrm{GPa}$ & $275 \mathrm{MPa}$ & $310 \mathrm{MPa}$ \\
\hline stainless steel & $192.98 \mathrm{GPa}$ & 0.30 & $85.978 \mathrm{GPa}$ & $250 \mathrm{MPa}$ & $540 \mathrm{MPa}$ \\
\hline
\end{tabular}

(6)

(1)

(1)

(1)

34
. . . . . .

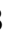




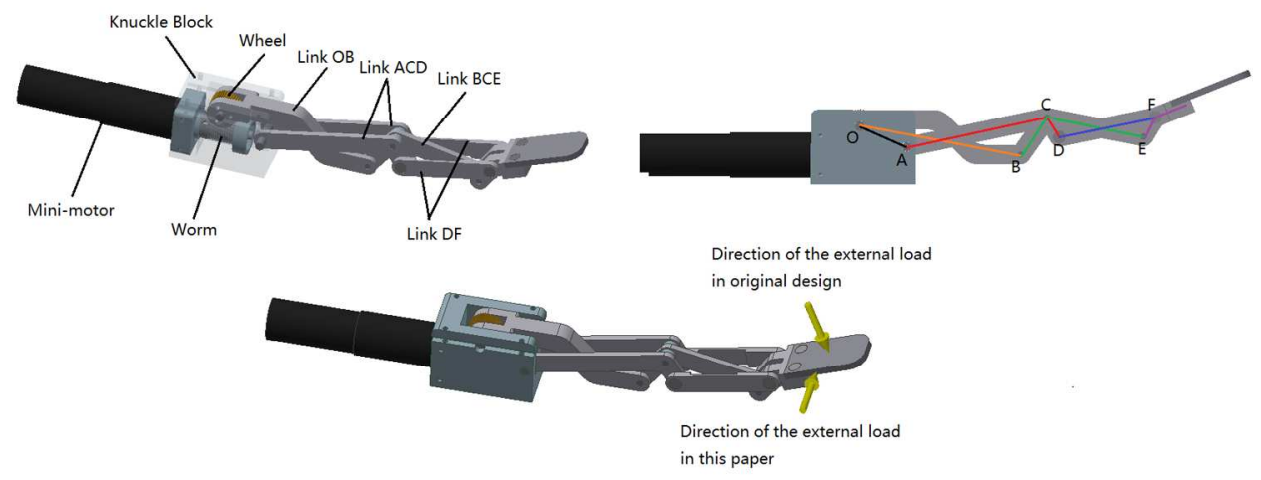

Figure 1, Structure of finger link system (left), key joint of the finger link system (right), direction of external load in original design and this paper (bottom)

$462 \times 176 \mathrm{~mm}(96 \times 96 \mathrm{DPI})$ 


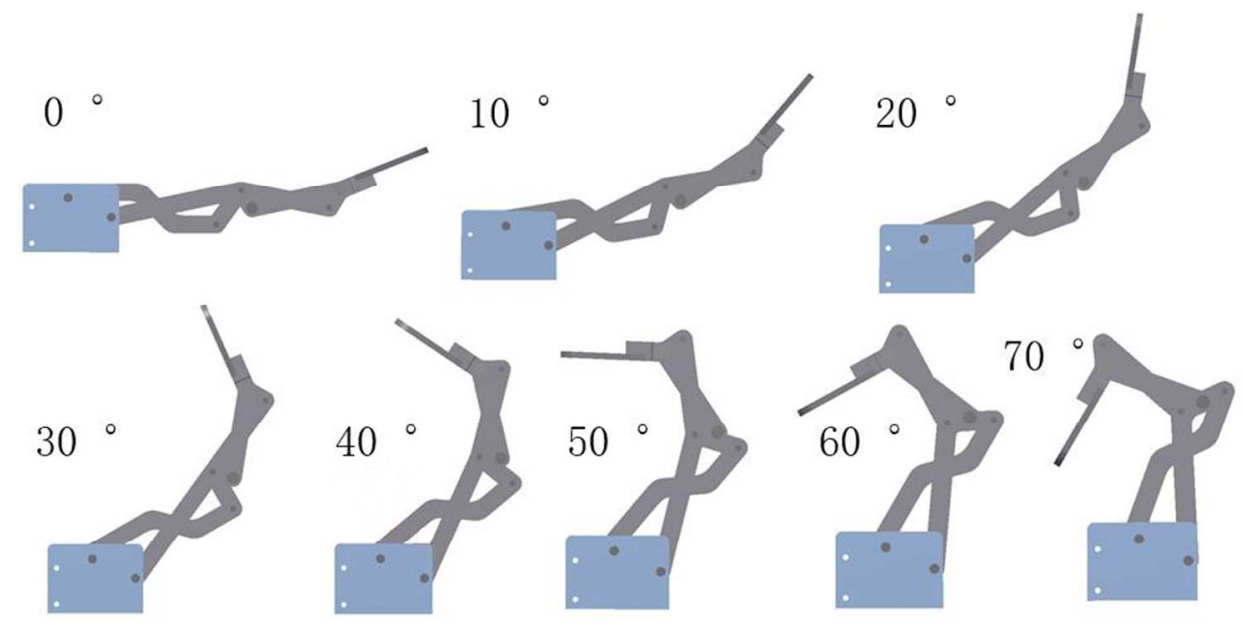

Figure 2, Modified link parts, Link DF (left), Link BCE (middle), Link ACD (right) $270 \times 147 \mathrm{~mm}(96 \times 96 \mathrm{DPI})$ 

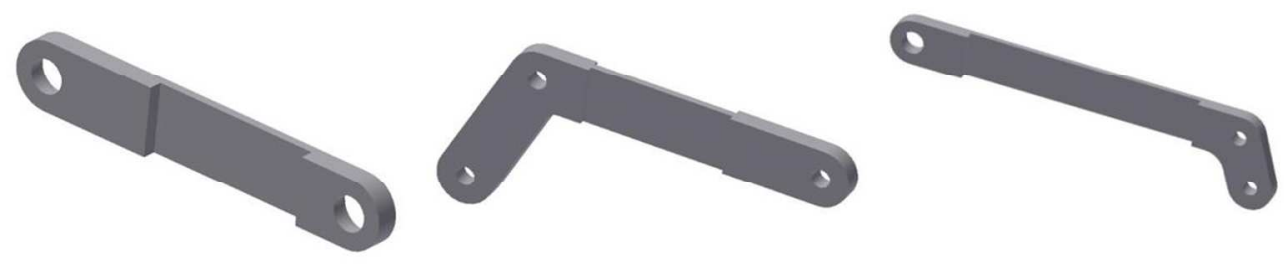

Figure 3, 8 finger link positions (the angle between the link OB and the upper surface of the knuckle block), the angle is the angle between the top surface of the knuckle block and top surface of link OB (the left straight part)

$321 \times 80 \mathrm{~mm}(96 \times 96 \mathrm{DPI})$ 
(b)
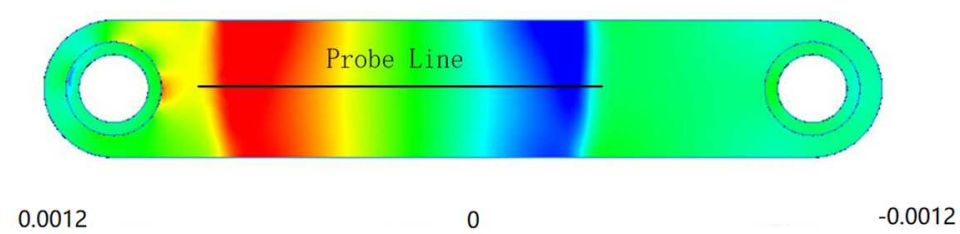

(a)

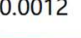

$-0.0012$

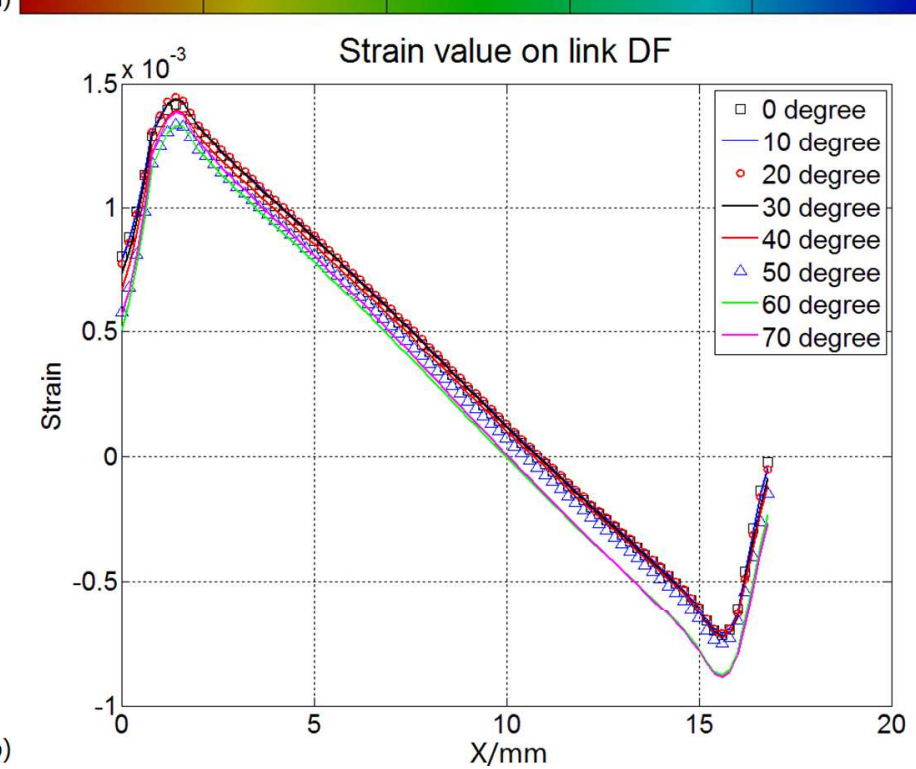

0.0012
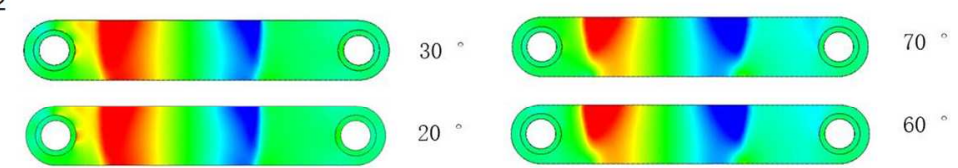

0

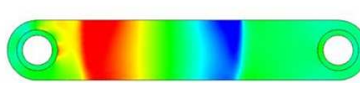

$10^{\circ}$

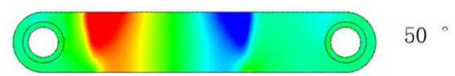

$-0.0012$
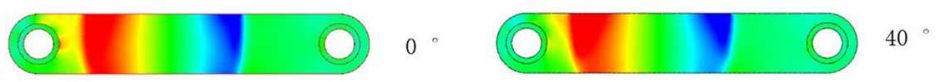

(c)

Figure 4, (a) Strain distribution on link DF, (b) Strain along the probe line. The angle indicates the closing operation, (c)Strain distribution on modified link DF during a curling operation

\section{$331 \times 452 \mathrm{~mm}(96 \times 96 \mathrm{DPI})$}


(a)
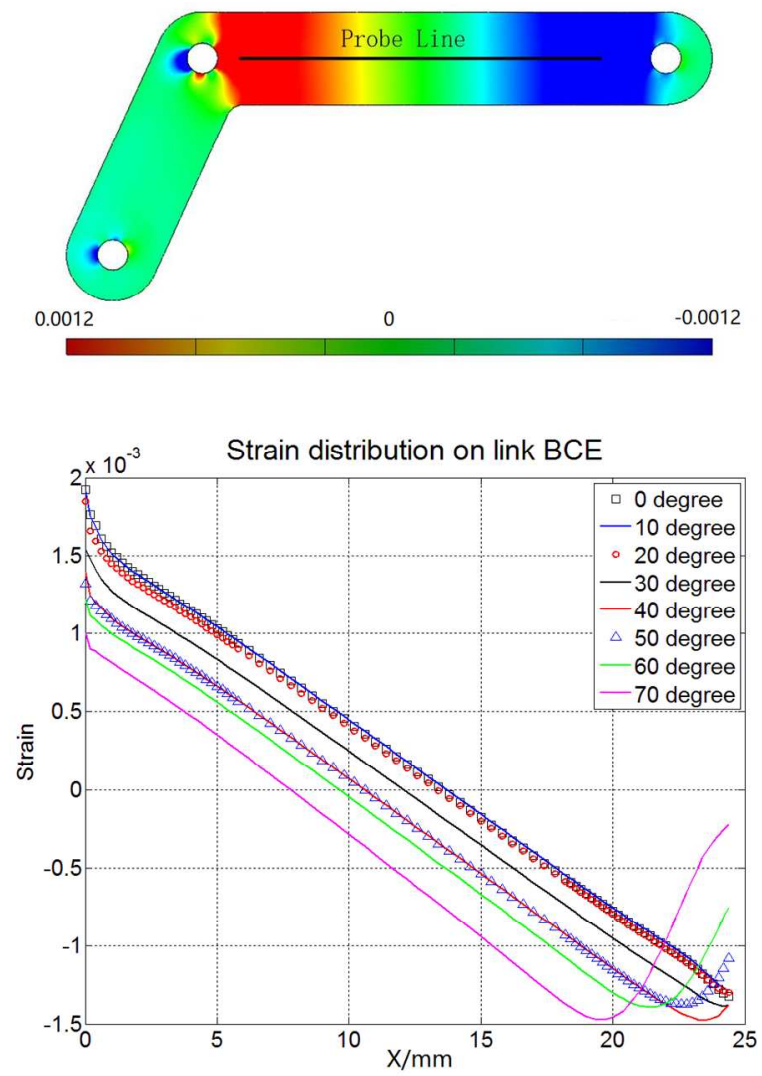

(b)

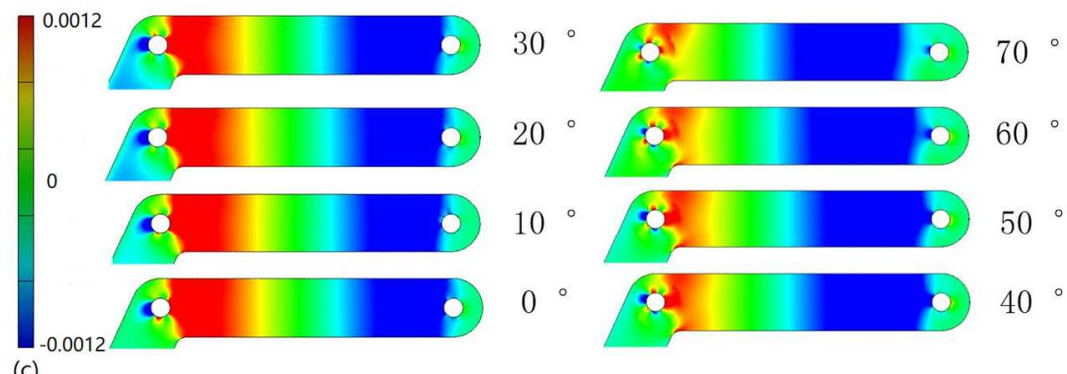

Figure 5, (a) Strain distribution on link BCE (modified link DF), (b)Strain distribution on link BCE (modified link DF), (c)Strain distribution on link BCE during a curling operation (modified link DF)

$365 \times 531 \mathrm{~mm}(96 \times 96 \mathrm{DPI})$ 
(a)
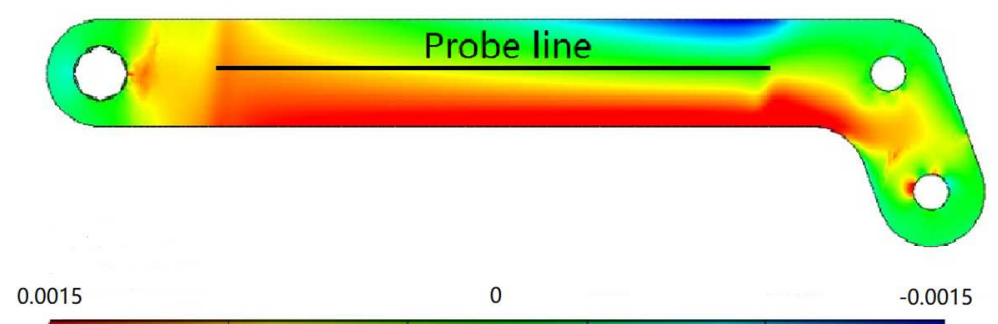

(b)
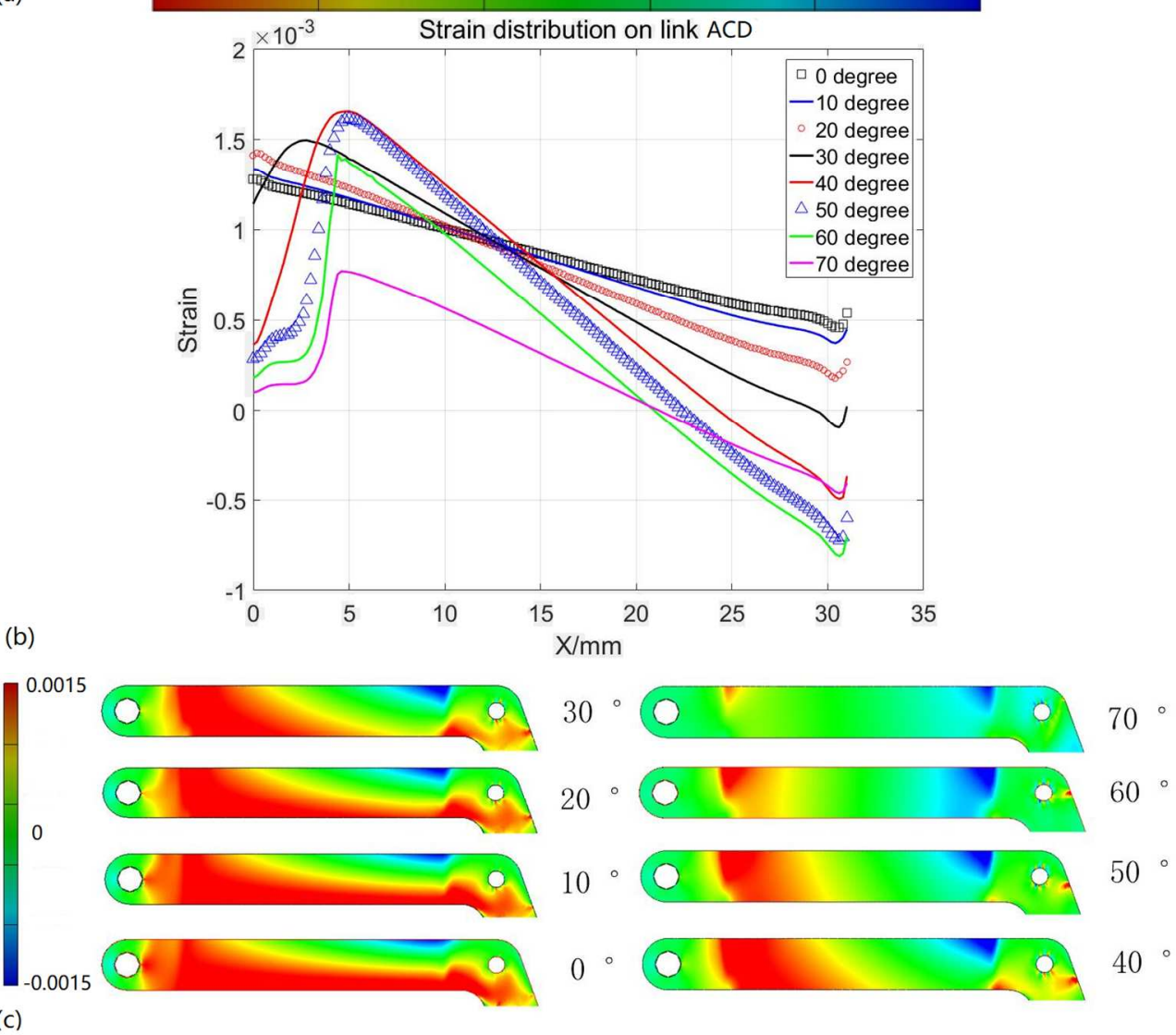

Figure 6, (a) Strain distribution on link ACD (b) Strain along the probe line. The angle indicates the curling operation, (c)Strain distribution on modified link ACD during a curling operation

$397 \times 455 \mathrm{~mm}(96 \times 96 \mathrm{DPI})$ 
(a)
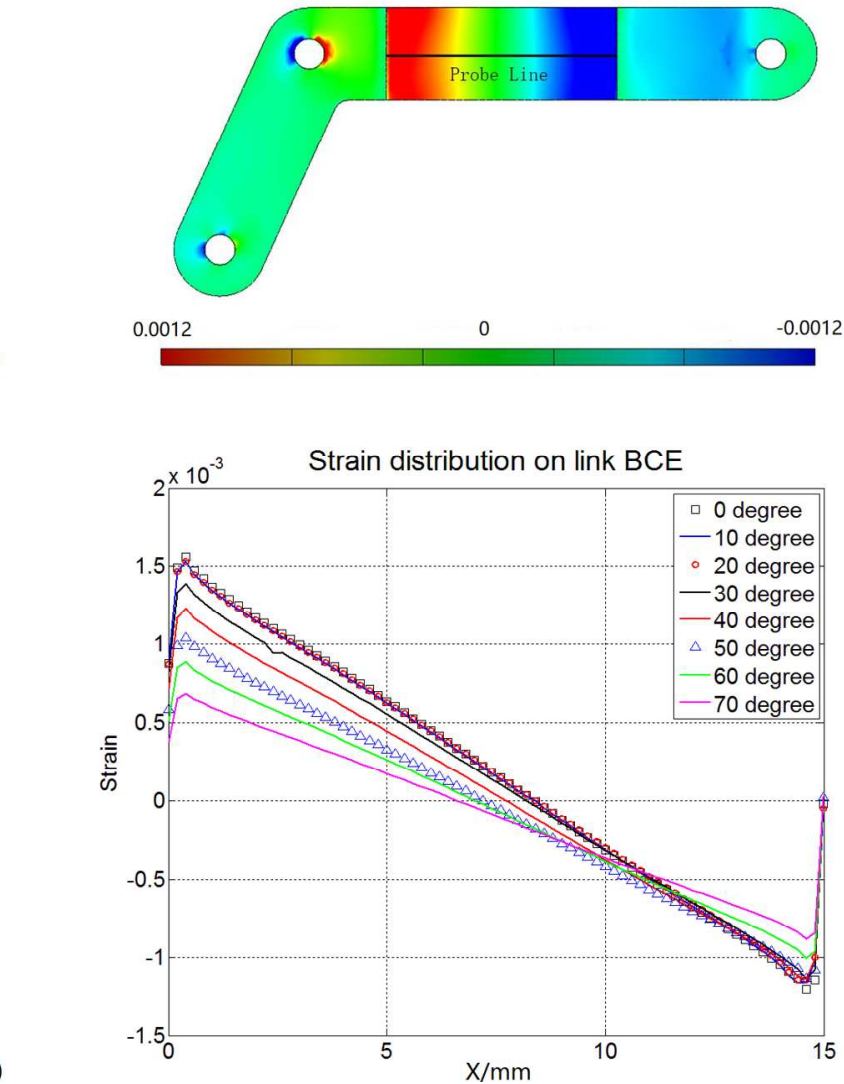

(b)

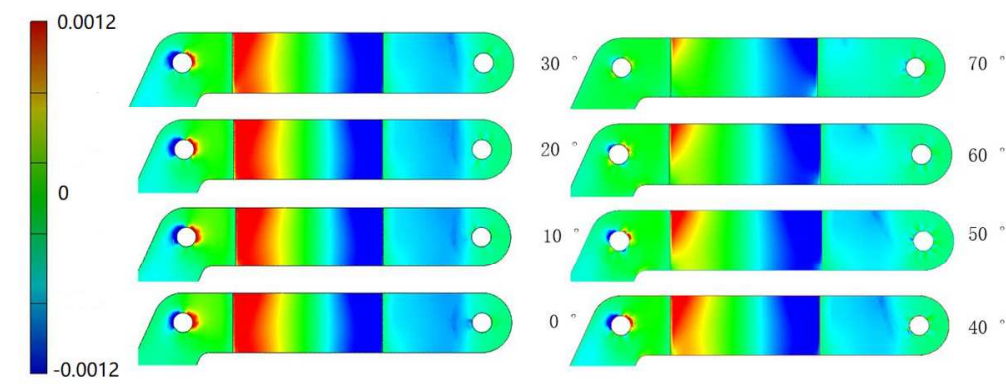

(c)

Figure 7, (a) Strain distribution on link BCE, (b) Strain value along the probe line. The angle indicates the curling operation, (c)Strain distribution on modified link BCE during curling operation

$361 \times 533 \mathrm{~mm}(96 \times 96$ DPI) 


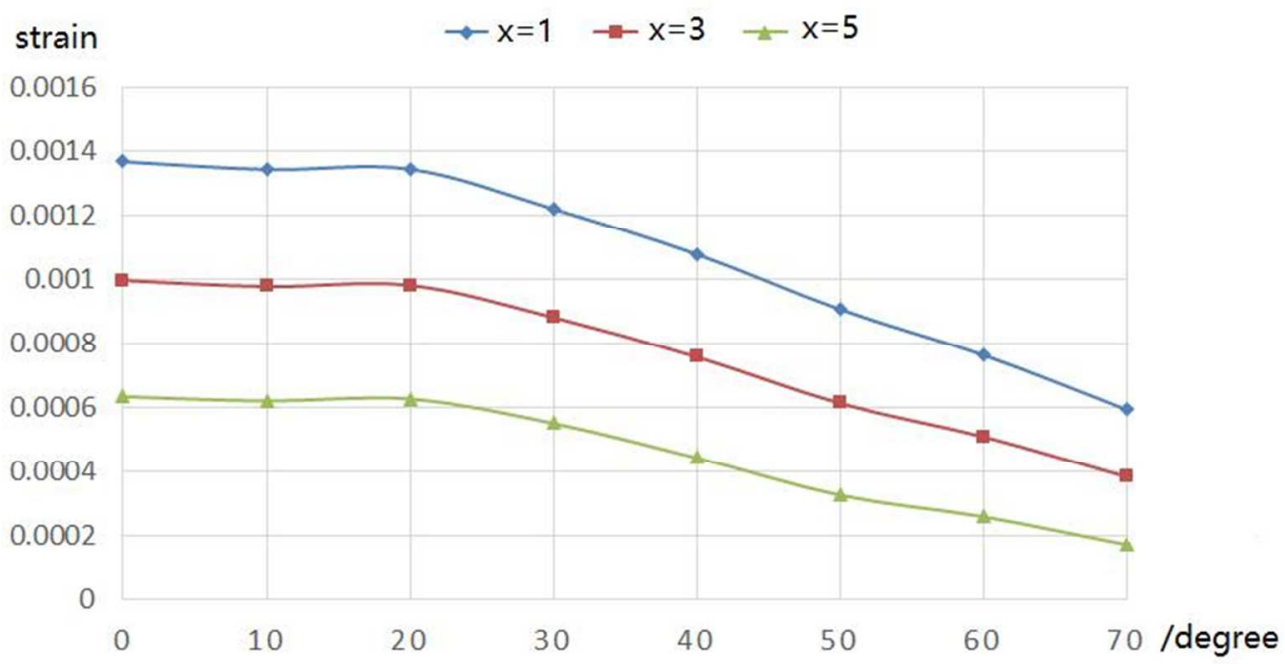

Figure 8, The strain data at certain positions with different curling angle of the finger $209 \times 112 \mathrm{~mm}(96 \times 96$ DPI $)$ 
(b)

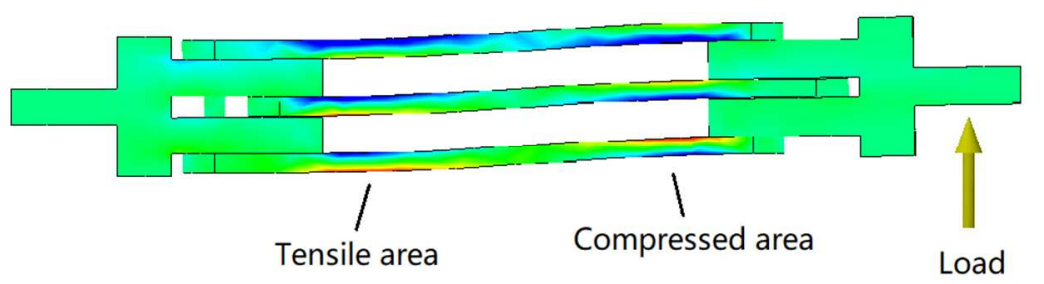

(c)

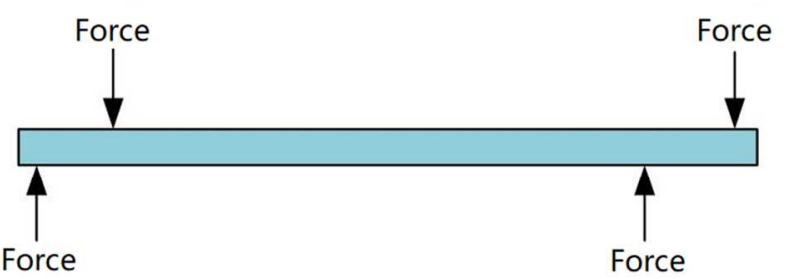

Figure 9, (a)The simplification of the original link system, (b)The simulation result of simplified module, top view, the displacement is enlarged twice to make it easier to observe, (c)The simplified forces applied on the side link

$318 \times 261 \mathrm{~mm}(96 \times 96 \mathrm{DPI})$ 
Referee: 1

1. For "This paper is not well written. The English is poor and non scientific throughout. A number of the diagrams are not very clear with some writing on the diagrams being too small to read. e.g. Fig 2 40degs. All of these areas need to be addressed before the article could be published. At present the whole article is not easy to read and is rather confusing. "

The paper is rewritten and a lot of changes have been made. Section set is changed to make the paper easier to understand. The use of language is reconsidered to be more scientific. The numbers of the diagrams are changed to bigger size.

2. For "Page2 Line 38. The reference to the Southampton hand work is only a conference publication despite much work having been done prior to that quoted. The sentence starting 'The Southampton hand ..... is poorly written. "

A journal paper is introduced here. A series of phd thesis, which are all related to the Southampton Hand project, are added. The sentence is rewritten.

3. For "In the introduction the tense keeps changing. When talking about previous research the past tense would seem to be the most appropriate, whereas here the present tense is often used. "

The tense in the introduction is all reconsidered. When talking about previous research the past tense is used. When talking about the artificial hand design, as it remains the same till now, presenrt tense is used.

4. For "The is no attempt made to put this work in context or to give a rationale why it was undertaken. Is it an attempt to dispense with a sensor on the side of the finger when a lateral prehension grip pattern is used? If so, this is not explained. The way in which the finger mechanism works should be described. "

The reason is presented in the introduction, paragraph 1. A bried introduction of the mechanism of the finger is added.

5. For "Simulation Page 4 line 37. A modified link is mentioned but this is not explained. However in Line 14 page 5, multiple links are referred to. "

The order of sections is rearranged. The finger link modification section is now located in section 2.1 .

6. For "Page 4 Line 44. I presume other parts refer to the whole finger. If so they should say so.

The order in which the three links are referred to varies throughout the paper which causes confusion. This should be kept constant both in the diagrams and in the text. 
The sentence is rewritten. The order in which trhe three links are referred is changed to the same through out the paper.

The order is:

Modified link DF with probe line on link DF

Modified link DF with probe line on link BCE

Modified link ACD with probe line on link ACD

Modified link BCE with probe line on link BCE

7. For "Page 5 line 5. The $\mathrm{x}$ axis is not defined on any of the diagrams. "

The $\mathrm{x}$ axis is defined in simulation section. It is defined in each case respectively.

8. For "Results Page 6 lines 35-39. This sentence is not clear and requires rewording and further explanation. Words like 'almost ', 'good' etc. are used throughout which are not scientific and should be avoided."

This section is relocated in discussion section. The sentence is rewritten to make the idea clear. Words like almost and good are replaced. 